\title{
Why Archives of Plastic Surgery?
}

\author{
Donna Savitry Lukman
}

Secretary General of Indonesian Association of Plastic Reconstructive and Aesthetic Surgeons Department of Plastic Surgery, Premier Bintaro Hospital, Tangerang, Indonesia

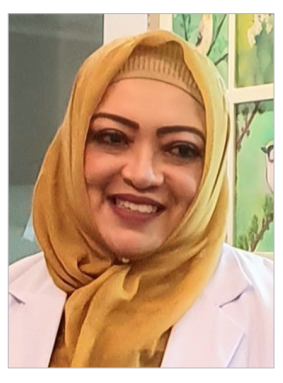

It was in the spring of 2017 when I came to Seoul for the first time and participated in PRS Korea 2017, the 75th Congress of the Korean Society of Plastic and Reconstructive Surgeons (KSPRS), which publishes Archives of Plastic Surgery (APS). I never imagined that this would be the first step in developing our relationship with Korean plastic surgeons. I met Jaewoo Park, an old friend whom I have known since my plastic surgery residency, and began to wonder: what can I do to help our societies become closer? We knew that some Indonesians come to South Korea to undergo plastic surgery and that South Korea is well known as a prominent leader of plastic surgery in Asia. I thought that we must foster close relationships with Korean plastic surgeons to exchange techniques.

Therefore, we began to build a relationship with KSPRS, which started at the Indonesian Association of Plastic Reconstructive and Aesthetic Surgeons (InaPRAS) annual meeting in Bali in 2018, with Dae Hyun Lew as the executive chairman of KSPRS. We finally succeeded in signing a memorandum of understanding (MOU) with KSPRS at PRS Korea in November 2019. This was a memorable occasion that brought about a fruitful connection between our societies.

We have exchanged speakers for our annual meetings, and we support each other in scientific matters. InaPRAS feels like it has a big brother that guides us in the ways of science. On top of this, we have the opportunity of making APS our official journal. This is something big: we have been offered to co-manage the journal, and we will have a good venue to publish our members' research.

I truly hope that we will be able to learn a lot from APS, and hopefully, someday we will also have our own journal that has an impact number as high as APS — who knows?

\section{NOTES}

\section{Conflict of interest}

No potential conflict of interest relevant to this article was reported.

\section{ORCID}

Donna Savitry Lukman

https://orcid.org/0000-0003-0667-0315
Correspondence: Donna Savitry Lukman

Department of Plastic Surgery, Premier Bintaro Hospital, Tangerang 15224, Indonesia

Tel: +62-21-27625500, E-mail: rasendriyad@yahoo.com

Received: May 7, 2021 • Revised: May 12, 2021 • Accepted: May 13, 2021

pISSN: 2234-6163 • elSSN: 2234-6171

https://doi.org/10.5999/aps.2021.00787 • Arch Plast Surg 2021;48:244 